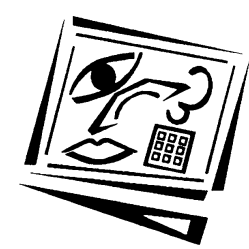

\title{
The emergence of an online learning community in first year tertiary studies in psychology
}

\author{
Dale Holt, Mary Rice and Christine Armatas \\ Deakin University
}

\begin{abstract}
The introduction of an online supported, resource based learning environment into a large, multi-modal first year psychology unit led to the spontaneous development of a small, but active, learning community. While off campus students were more active online contributors, many other students "observed" these interactions, not actively contributing but finding the discussion postings valuable to their learning. Overall, use and perceived value of the online communication facilities were related to how confident students were that they had an appropriate study strategy, with off campus and older students reporting greater confidence in their study approach. The results highlight that the nature and function of learning communities for large, multi-modal foundation units are quite different to those typically articulated in the literature and are worth further investigation.
\end{abstract}

\section{Introduction}

First year psychology at Deakin University is a very large unit offered across three campuses in three Victorian cities, and off campus nationally and internationally, with an overall student enrolment of around 1000. During 2001-2002, research was conducted on the impact of introducing an online resource based learning (RBL) approach into this unit. The focus of this paper is the impact of those aspects of the RBL environment designed to create and sustain communication and collaboration between teachers and students. In particular, data is presented on the nature of a spontaneously developing online learning community, based around the communications facilities provided in a learning management system (LMS). Students' use and perception of the value of communication facilities are examined as a function of mode of study (on and off campus), age, learning goals, study approaches, and attitudes to computers. The results highlight the unique aspects of large, foundational units delivered in multiple modes, and the challenges such courses present to developing and sustaining learning communities. These learning communities must help students understand the fundamentals of a discipline and foster 
independent learning. The implications of the findings are considered with reference to key issues associated with the implementation of online enhanced RBL environments for large, first year multi-modal courses.

\section{Challenges in situating online learning communities in first year, multi-modal, discipline based courses}

According to Harasim et al. (1995) the communication flows enabled by online learning communities promote social interactions and intellectual stimulation, and provide a means for sharing insights, concerns, problems and solutions. Similarly, Wenger (1998) sees both physical and virtual communities as characterised by mutual engagement, with a shared repertoire towards a joint enterprise. Given the challenges associated with creating and maintaining such communication between students studying at a distance, it is not surprising that research has focused on collaborative or online supported cooperative learning in open, flexible and distance education. In this field, online learning communities have been explored principally in three significant contexts:

- Postgraduate professional coursework programs in fields like management, adult education, and open, distance and flexible education (Harasim, 1989; Bird, 2001; McConnell, 2000; Salmon, 2000; Stacey \& Fountain, 2001; Stacey \& Rice, 2002);

- Undergraduate foundation courses on information and communications technologies (ICT) where ICTs are the key object of study in the curriculum and the courses are offered at a distance, significantly online (Mason, 1989; Thorpe, 1998; Weller, 2001);

- Undergraduate discipline based, multi-modal (i.e. offered on and off campus) courses where online learning communities are designed to support specifically the off campus student cohort (Graham \& Scarborough, 2001).

In the first two contexts, ICTs are either integral to the curriculum or are a key object of study. The first context assumes participants engaging in advanced professional development, using opportunities for online collaboration to enhance their professional conceptions and practices. At the undergraduate level, the third context gives special attention to the online learning community for the off campus student cohort only. Another context yet to be systematically investigated is the development of online learning communities for large, multi-modal, discipline based courses. We believe that the learning communities that develop in large foundation units serve different functions and have different characteristics to those typically articulated in the literature. Interacting with inexperienced students to build understanding of discipline concepts would seem to involve different challenges to those involved in engaging more mature, experienced students with an online learning community to 
develop understanding of professional practice contexts. However, many benefits can be expected from students engaging with an online learning community at first year level. These include opportunities to share ideas, clarify and extend difficult concepts, provide and receive encouragement, motivation and performance feedback from both peers and staff, and to decrease the isolation felt by some students.

\section{The online learning community and the course's RBL environment}

The commitment to creating opportunities for student-teacher and student-student interactions was part of a broader plan to create an online supported RBL environment for first year psychology (see Holt et al., 2002). The learning environment consisted of pre-packaged learning resources, a communication environment (announcement and discussion spaces), and face to face classes for on campus students. Since the range of resources was quite extensive, it was anticipated students would exercise choice within the time constraints imposed by their study timetable. In designing the online environment, it was expected that both on and off campus students would use the announcements to keep abreast of developments in the unit, and to receive feedback and information from the Unit Chair. Off campus students were expected to make the most use of the discussion spaces, since on campus students regularly attended face to face classes. Contributions to the discussions were optional because no additional staff were available to moderate discussion groups online for all students enrolled.

The computer mediated communication facility in the LMS was one element in the online supported resource based learning approach implemented in the unit. Since the use of this element of the learning environment was not mandated, we were interested in exploring the factors associated with its use. Of interest were differences as a function of study mode, age, approaches to learning and attitudes to computers. The study reported here investigated the spontaneous development of an online learning community in the context of a course innovation that included the provision of a range of resources with different delivery formats, including print and electronic formats.

\section{Method}

\section{Participants}

Table 1 shows a breakdown of the participants in the study. The disproportionate numbers of females $(\underline{\mathrm{n}}=602)$, with only 109 males (18 participants did not provide their gender) taking part in the study, is typical of enrolment patterns in this unit. 
Table 1: Breakdown of sample by age

\begin{tabular}{|c|c|c|c|}
\hline \multirow{2}{*}{$\begin{array}{c}\text { Age Group } \\
\text { (years) }\end{array}$} & \multicolumn{3}{|c|}{ Frequency $(\%)$} \\
\cline { 2 - 4 } & $\begin{array}{c}\text { On campus } \\
(\underline{\mathrm{n}}=634)\end{array}$ & $\begin{array}{c}\text { Off campus } \\
(\underline{\mathrm{n}}=53)\end{array}$ & $\begin{array}{c}\text { Total } \\
(\mathrm{N}=687)\end{array}$ \\
\hline $18-20$ & $538(85 \%)$ & $16(30 \%)$ & $554(79 \%)$ \\
\hline $21-25$ & $51(8 \%)$ & $10(19 \%)$ & $61(9 \%)$ \\
\hline $26-35$ & $32(5 \%)$ & $18(34 \%)$ & $50(8 \%)$ \\
\hline over 35 & $13(2 \%)$ & $9(17 \%)$ & $22(4 \%)$ \\
\hline
\end{tabular}

Most students in the sample were studying on campus, with $58(8 \%)$ enrolled in off campus mode. The on campus students were younger; $85 \%$ of them were aged 18 to 20 years, compared to only $30 \%$ of off campus students.

\section{The research instrument}

A detailed research instrument was compiled containing 160 closed and 5 open ended questions. On campus students took part in the study in the tutorial held the second last week of semester. At that time, the research instrument was mailed to off campus students and completed forms were returned in a reply paid envelope. All responses were anonymous.

The instrument consisted of three sections. The first section included items that assessed students' study habits; where students accessed the online resources; amount of time spent working with the online learning environment; difficulty in accessing, using and navigating around the online system; and students' usage and perceptions of the value of the print, digital and online learning resources which constituted the overall RBL approach.

The second section assessed students attitudes to computers, which were measured using the Computer Attitude Scales (CAS) (Loyd \& Gressard, 1985). These scales assess each student's computer confidence, liking, and anxiety, and the extent to which they perceive computers are useful.

The third section measured students' learning goals, study strategies and interest in psychology. Learning goals were measured using the Learning Goals scales developed by Harackiewicz et al (2000). This measure consists of three scales. First, Mastery measures the extent to which students focus on learning and developing skills. Second, Performance assesses the extent to which students self report that they engage in behaviours designed to demonstrate competence. Third, Work Avoidance assesses the extent to which a student's goal is to engage in avoidance behaviours or minimise effort. Students' study strategies were measured using the Study Strategies scales developed by Harackiewicz et al. (2000). Students' self reported use 
of three study strategies is assessed with this measure. The Elaboration scale assesses the extent to which students report they try to explain key concepts in their own words, make connections between new and previously learned knowledge and try to relate concepts together. The Rehearsal scale measures the extent to which students report they use surface strategies such as memorisation and repetition to study for the course. The third scale, Lack of Strategy, measures whether a student feels they lack an appropriate study strategy for the course. Interest in Psychology was measured using Harackiewicz et al.'s (2000) Interest in Psychology scale. It measures the student's enjoyment and satisfaction with the psychology course in which they are enrolled.

Preliminary data analysis included calculation of summary scores for the scales making up each of the measures included in the research instrument. The descriptive statistics and results of the reliability analysis for the entire sample for each scale are shown in Table 2. All the scales except Work Avoidance showed good reliability. Given the poor reliability of the Work Avoidance scale (alpha $=.51$ ), this measure was not included in further analyses. Several statistical techniques were used to analyse the research data. Where on and off campus students were compared on one measure or score, a $t$-test for independent samples was used. For comparison of the two groups on multiple variables, multivariate analysis of variance (MANOVA) was used. For both types of analyses, all assumptions underlying the analyses were tested and met.

Table 2: Scale means and reliability coefficients for the Goals, Study Strategies, Interest and Computer Attitudes Scales

\begin{tabular}{|l|c|c|}
\hline \multicolumn{1}{|c|}{ Scale } & $\begin{array}{c}\text { Mean } \\
\text { (Standard deviation) }\end{array}$ & $\begin{array}{c}\text { Cronbach's } \\
\text { Alpha }\end{array}$ \\
\hline Learning Goals & $24.2(3.6)$ & .76 \\
Mastery & $19.8(5.1)$ & .81 \\
Performance & & \\
\hline Study Strategies & $20.4(3.3)$ & .82 \\
Elaboration & $18.1(4.1)$ & .74 \\
Rehearsal & $10.5(3.2)$ & .80 \\
Lack of strategy & $35.3(7.6)$ & .88 \\
\hline Interest in psychology & & .88 \\
\hline Computer Attitudes Scale & $32.7(7.5)$ & .73 \\
Computer confidence & $29.4(6.2)$ & .90 \\
Computer liking & $35.2(7.9)$ & .82 \\
Computer anxiety & $38.2(5.8)$ & \\
Computer usefulness & & \\
\hline
\end{tabular}




\section{Results of study: Comparisons of on and off campus student cohorts}

\section{Reported study patterns}

No significant difference was found between on and off campus students for the percentage of study time spent online. On campus students spent on average $43.7 \%(s d=27.4)$ of their time studying using a computer, compared to $38.9 \%(s d=27.0)$ for off campus students. However, a significant difference between on and off campus students for total number of study hours was found, $t(685)=7.5, p<.001$, with off campus students reporting on average a greater number of hours study each week spent studying psychology $(m=6.4, s d=3.4)$. On campus students in comparison spent an average of 3.8 hours $(s d=2.4)$ studying for the unit.

\section{Usefulness of the announcement tool}

Only the Unit Chair was able to post announcements; all students and other teaching staff could read them. Announcements included a welcome to the unit, an explanation of the advantages of the online format, suggestions about how to best use the unit resources, and advice about using the Student Manual and Study Guide. Instructions were provided about using the discussion area effectively, how to view the online videos, and how to work with the LMS and the Electronic Warehouse CD. Several announcements related to assignments and exam preparation.

The majority of students (on campus $77.0 \%$, off campus $88.1 \%$ ) reported they read the announcements posted by the chair. As summarised in Table 3 , over $50 \%$ of on campus and $80 \%$ of off campus students who read them found them useful or very useful. The following comments provided some reasons for this.

- Announcements from course lecturer were interesting and often vital.

- It saved chasing up tutors for information.

- I found the announcements to be relevant and concise.

- Announcements occasionally clarified a question. Kept me up to speed with dates.

- Being an off campus student these resources allowed contact with the course adviser and additional information for the course.

However, $25 \%$ of on campus and only $7 \%$ of off campus students who read them reported they were not useful as suggested in these comments:

- They seemed to give information that was unclear or unnecessary.

- It was time consuming because there were too many. 
Table 3: Usefulness of announcements

\begin{tabular}{|c|c|c|}
\hline & $\begin{array}{c}\text { On campus } \\
\underline{\mathrm{n}}(\%)\end{array}$ & $\begin{array}{c}\text { Off campus } \\
\underline{\mathrm{n}}(\%)\end{array}$ \\
\hline $\begin{array}{l}\text { Read the announcements in the LMS } \\
\text { Yes } \\
\text { No } \\
\text { Missing }\end{array}$ & $\begin{array}{c}488(77.0 \%) \\
136(21.4 \%) \\
10(1.6 \%)\end{array}$ & $\begin{array}{c}47(88.1 \%) \\
6(11.9 \%) \\
-\end{array}$ \\
\hline \begin{tabular}{|l} 
Perceived usefulness of announcements \\
Not at all useful \\
Not useful \\
Useful \\
Very useful \\
No response \\
\end{tabular} & $\begin{array}{l}15(3.0 \%) \\
110(22.5 \%) \\
246(50.5 \%) \\
23(4.7 \%) \\
94(19.3 \%)\end{array}$ & $\begin{array}{c}1(2.4 \%) \\
3(4.8 \%) \\
27(50.0 \%) \\
16(31.0 \%) \\
6(11.8 \%) \\
\end{array}$ \\
\hline
\end{tabular}

\section{Usefulness of the discussion spaces}

The online discussion spaces were designed to provide opportunities for discussion in content areas, clarifying course requirements, conducting social discourse, and solving technical and access difficulties. Content analysis indicated that discussion messages covered a broad range of issues. While very small relative to the entire psychology student population, a very active community of students developed over the semester, discussing topics of a broad and sometimes provocative nature. For example, the Social Psychology module generated discussion about a variety of matters, including the Stanford Prison experiment, late term abortion and autism. There were 17 messages posted, but as shown in Table 4, many more read them and found them useful. Similarly the History of Psychology unit generated discussion by 12 students after the Unit Chair posted some challenging questions. The nature of these discussions was indicative of the level of interest and commitment within this online community and could be interpreted as positive and reflective of the kind of robust, online learning community at work, as characterised by Harasim et al. (1995) and Wenger (1998).

Many messages (94) focused on one of the learning activities and the assignment requirements. Others sought help finding the timetable, navigating the Electronic Warehouse, finding the lecture notes and relevant chapters to read. Closer to exam time there were 35 messages relating to the exam, such as what material would be examinable.

A separate discussion folder was created for students to post messages regarding technical assistance. In this, there were 24 messages, mostly airing grievances about difficulties in finding coursework online and technical problems with the LMS. Many messages asking for assistance 
were answered by other students, sometimes with quite detailed instructions and encouragement.

Comments from the survey and discussion areas indicated that some students had no problems working online and found the experience enjoyable. Many appreciated the convenience the LMS provided, because all study materials were at their fingertips, and time was saved by not having to attend a library, queue for a photocopier, or find lecturers on campus. In particular off campus students were able to interact formally with others studying the unit for the first time. However, other students found online learning was time consuming. Some were confused about how to negotiate all the online resources and felt they wasted time looking for what they needed. They would have liked a tutorial on how to approach their learning.

Overall, the discussion postings were read by over half the students. A higher proportion of off campus than on campus students who read them reported them to be useful (see Table 4). Students' comments provided some reasons for this.

- At one stage I had about three questions to ask, so I checked the discussion page before asking the lecturer. I found all my answers from reading the discussion pages. It was great!

- It was helpful to figure out different problems and communicate with other students and to find out what we should be doing.

- It is important to know that others may be having the same problem with the course. The online discussion at the end of the semester was great.

On campus students were much less likely to find the discussion spaces useful; $66 \%(\underline{n}=206)$ who read them did not value them, compared with $37 \%(\underline{n}=15)$ of off campus students (see Table 4$)$. As some students commented:

- I only had time to do the essentials.

- There was a problem with the amount of messages that were pretty irrelevant and a waste of time.

- Discussion sometimes confused matters - especially at the start of the course where ...it was difficult to see the overall structure of the course.

It was not possible to obtain usage statistics from the learning management system for this study. Nonetheless, data suggest that usage levels warranted the continued inclusion of unit based discussion opportunities. 
Table 4: Usefulness of discussions

\begin{tabular}{|l|c|c|}
\hline & On campus & Off campus \\
\hline Read the discussions in the LMS & $\underline{\mathrm{n}}=634$ & $\underline{\mathrm{n}}=53$ \\
Yes & $374(59 \%)$ & $40(77.0 \%)$ \\
No & $247(39 \%)$ & $11(22.6 \%)$ \\
Missing & $13(2 \%)$ & $2(0.4 \%)$ \\
\hline Perceived usefulness of discussions & $\underline{\mathrm{n}}=314$ & $\underline{\mathrm{n}}=40$ \\
Not at all useful & $60(19.0 \%)$ & $7(17.5 \%)$ \\
Not useful & $146(46.6 \%)$ & $8(20.0 \%)$ \\
Useful & $97(31.0 \%)$ & $17(42.5 \%)$ \\
Very useful & $11(3.4 \%)$ & $8(20 \%)$ \\
\hline
\end{tabular}

\section{Learner characteristics and the perceived usefulness of online communication}

Correlations were performed to investigate possible relationships between study goals and approaches, interest in the unit of study, and perceived usefulness of the announcement and discussion messages. As shown in Table 5, across the entire sample, perceived usefulness of announcements was related to interest, while confidence in how to approach studying for the unit was significantly related to perceived usefulness of both the announcements and discussions.

Table 5: Spearman's correlations between learner characteristics and perceived usefulness of online communication facilities in the LMS

\begin{tabular}{|c|c|c|}
\hline $\begin{array}{c}\text { Learning approaches and } \\
\text { study strategies }\end{array}$ & Announcements & Discussion messages \\
\hline Interest in psychology & .176 & .163 \\
\hline $\begin{array}{l}\text { Study goals } \\
\text { Mastery } \\
\text { Performance }\end{array}$ & $\begin{array}{l}\text { ns } \\
\text { ns }\end{array}$ & $\begin{array}{l}\text { ns } \\
\text { ns }\end{array}$ \\
\hline \begin{tabular}{|l|} 
Study strategies \\
Elaboration \\
Rehearsal \\
Lack of strategy
\end{tabular} & $\begin{array}{c}\mathrm{ns} \\
\mathrm{ns} \\
-.175\end{array}$ & $\begin{array}{c}\mathrm{ns} \\
.137 \\
-.119\end{array}$ \\
\hline \multicolumn{3}{|c|}{$\begin{array}{l}\text { Note: Since multiple correlations were conducted a Bonferoni adjustment } \\
\text { (significance level/number of tests) was made to control for Type I error rate, with } \\
\text { the resulting significance level being .008. ns indicates the correlation is not } \\
\text { significant (i.e. p }>.008 \text { ) }\end{array}$} \\
\hline
\end{tabular}

Use of rehearsal as a study strategy was also significantly correlated with perceived usefulness of the discussion messages. These results suggest that the more interested students were in the psychology course, the more value they placed on the announcements. The more confident students were that they had a strategy for studying for the unit, the more useful 
they perceived the online communications. Interestingly, students who reported greater use of rehearsal as a study strategy also perceived the discussions to be more useful, perhaps because they reinforced or repeated previous learning.

Possible relationships between perceived usefulness of the online communication facilities and attitudes to computers were also investigated using correlations. As shown in Table 6, perceived usefulness of discussions was significantly correlated with all four measures of attitudes to computers. The more confident students were using computers, the more useful they found them, and the more they liked working with computers, the greater the perceived usefulness of the communications facilities. Similarly, lower computer anxiety was related to greater value being placed on the usefulness of both the announcements and discussion messages. The same pattern of relationships was found for usefulness of announcements, except that computer confidence was not significantly correlated with perceived usefulness of announcements. These relationships suggest positive attitudes to computers are related to more positive attitudes to the usefulness of the communication facility.

Table 6: Spearman's correlations between attitudes to computers and perceived usefulness of online communication facilities in the LMS

\begin{tabular}{|l|c|c|}
\hline \multicolumn{1}{|c|}{ Computer Attitude Scales } & Announcements & Discussion messages \\
\hline Computer confidence & $\mathrm{ns}$ & .173 \\
\hline Computer liking & .196 & .249 \\
\hline Computer usefulness & .206 & .155 \\
\hline Computer anxiety & .122 & .136 \\
\hline $\begin{array}{l}\text { Note: Higher scores on all measures indicated more positive attitudes. Since } \\
\text { multiple correlations were conducted, a Bonferoni adjustment (significance } \\
\text { level/number of tests) was made to control for Type I error rate, with the resulting } \\
\text { significance level being .006. ns indicates the correlation is not significant (i.e. } p> \\
\text {.006) }\end{array}$ \\
\hline
\end{tabular}

\section{Key issues and implications of findings}

As first year psychology at Deakin exemplifies, increasingly in dual mode institutions, designing and facilitating online learning communities must be seen in the context of broader RBL type approaches catering for the different needs of diverse student cohorts in dispersed study locations on and off campus. While a suite of print, digital and online learning resources may be common to all student cohorts, as in first year psychology, opportunities exist with the newer corporate online teaching/ learning systems to adapt aspects of the online environment to different learning needs. Online learning communities might relate to an entire unit 
(or program, school, faculty, university and beyond) and provide all student groups with opportunities to interact beneficially with each other irrespective of differences in modes of study, learning goals, learning approaches, and life and work experience. In this respect, online learning communities broaden educational experiences and capacity development. On the other hand, differences in student cohorts can also be recognised and further opportunities for interaction could be established for on campus students based on their local physical communities of teaching/ learning. Their local lecturers, tutors and significant other academic service providers, could facilitate such online communities. These communities could help deepen the educational experience for such local groups, and further develop students' capacities to master the foundation knowledge and modes of enquiry of the discipline.

In relation to school leaver undergraduates, McInnis (2001) observes they are spending less time on campus and more time in paid employment. This pattern of disengagement with traditional on campus student life is leading to a 'loss of a critical mass in the learning community of the campus based universities' (McInnis, 2001, p.5). These days, students have a steep learning curve. They have to learn discipline knowledge, what it means to be a university student, how to study online, how to use technical systems, how to optimise use of resources, and how to become independent learners. McInnis (2001) calls for new forms of student engagement in university requiring, inter alia, more strategic and planned approaches to creating and managing learning communities. With students spending less time on campus, there are less opportunities for informal, spontaneous interactions amongst students and teaching staff for academic and social purposes. Data from this research suggest the online environment provides one avenue for the re-connection of participants in the educational process to further enhance on campus classroom interactions, with a broader range of experience and expertise offered by their off campus colleagues in the online classroom. Well designed integration between face to face classes and online learning activities could ensure a continuity of valued personal relationships throughout on campus students' studies.

The value of participating in online learning communities is usually associated with active engagement in discussions that challenge and extend ideas and understandings (e.g. Harasim et al., 1995; Salmon, 2000). While most of the active participants in the psychology learning community were off campus students, a small group of on campus students also made regular, significant contributions. A core group was involved in most discussions, with irregular contributions made by other students at various times. The data shows a large number of students read the messages and valued this activity, although they did not contribute to 
the discussion. In many respects, the learning community that developed as a result of exposure to the online RBL approach modeled the traditional face to face experience - some students made vocal and active contributions, while others watched and listened with interest but seldom contributed. Even though students were not directed to use the discussion area, and usage was not linked to formal assessment, many still saw value in either contributing themselves, or reading the contributions of others. The level of interest in, and value derived from the online community therefore exceeded design expectations.

While the majority of on campus students did not actively participate online, they did read the online communications. This suggests that a carefully designed online learning community potentially could alleviate some of the patterns of disengagement in the undergraduate experience, or, referring to Wenger (1998), lead to stronger forms of mutual engagement beyond peripheral involvement. This implies it is worthwhile continuing with and expanding the online learning community, irrespective of the number who actively engaged. Despite the signs of disengagement referred to by McInnis (2001), data from this research about engagement online indicate students are perhaps looking for a different type of engagement, one that offers more flexibility and choice.

Data also suggest attitudes to computers affect the reactions of learners to computer mediated learning. The results of the current study show that more positive attitudes to computers and lower computer anxiety are related to more positive perceptions of the communications environment. Similarly, other learner characteristics, such as subject interest, and study goals and approaches, are also related to students' perceptions of the learning environment. Experiences with the introduction of an online enhanced RBL approach in first year psychology show students will be selective in the choices they make, about what resources they use, and the level of interaction they have within a learning community. Those they perceive to be directly relevant to meeting the learning and assessment objectives of the course are used most frequently. However, other resources, such as discussion facilities, are also perceived as valuable, though not directly relevant to assessment or academic progress in the course.

Clearly the development of a learning community requires not only a more sophisticated learning design, but also more sophisticated moderating techniques. The task of moderating online communication requires quite different skills from those used in face to face classrooms (Salmon, 2000). This implies that staff need more professional development in preparation for teaching online, rather than learning on the job. While much can be learned from experience, abundant 
information exists about moderation techniques, managing workload, and developing a learning community that becomes self sustaining. With large undergraduate classes, moderation of online discussions needs to be shared across staff members including tutors. In the psychology unit, the Unit Chair assumed sole responsibility for moderation. Just as with face to face tutorials, the presence of tutors in the online environment could assist the Chair, and may help to personalise the experience and encourage more students to engage in, or at least attend, online discussions. Irrespective of arrangements, all staff should be seen as operating in a total environment, not just practising as teachers of face to face classes.

The research data indicates the young on campus cohort were more likely to lack learning strategies than mature age and off campus students. They required more direction than the timetable gave them about what they had to do and when. Furthermore, their expectations of what it meant to study psychology were not aligned with what was expected of them. There is clearly a need for curriculum developers to design curriculum in ways that take account of the realities of being an undergraduate student today. First year students need assistance in developing appropriate study strategies, and they also need guidance about specific resources, their particular purposes, and how they should best be used. Through careful design, online learning communities can help to address these needs by acting as the 'hub' for engagement.

\section{Conclusion}

We believe a more proactive approach is required to foster the school leaver, on campus group to participate actively and skilfully in online discussions, in ways integrated with their classroom activities, but which also recognise the emerging need for greater flexibility experienced by even those who are purportedly in full time study. Clearly, different student cohorts might benefit from both common and differentiated opportunities for online communication and collaboration, depending on curriculum requirements and specific learning needs. Learning management systems contain features allowing teaching staff to structure, direct and prompt in a more timely and flexible fashion student engagements, both in their virtual and physical learning worlds, on campus, in the home and in the workplace. This facility to design for customisation and, indeed, personalisation of the learning experience in large first year, multi-modal courses with standardised curricula and formal assessment requirements points the way forward for new forms of online learning communities supportive of quality learning outcomes. 


\section{References}

Bird, L. (2001). Virtual learning in the workplace: The power of 'communities of practice'. In G. Kennedy, M. Keppell, C. McNaught \& T. Petrovic, (Eds). Meeting at the Crossroads. Proceedings of the 18th Annual ASCILITE Conference, The University of Melbourne, Australia, 93-100. http:/ / www.ascilite.org.au/conferences/melbourne01/pdf/papers/birdl.pdf

Graham, M. \& Scarborough, H. (2001). Enhancing the learning environment for distance education students. Distance Education, 22(2), 232-244.

Harachiewicz, J.M., Barron, K.E., Tauer, J.M. \& Carter, S.M. (2000). Short-term and long-term consequences of achievement goals: Predicting interest and performance over time. Journal of Educational Psychology, 92(2), 316-330.

Harisim, L. (1989). On-line education: A new domain. In R. Mason \& A. Kaye (Eds), Mindweave: Communication, Computers and Distance Education. Oxford: Pergamon, 50-62. http://icdl.open.ac.uk/literaturestore/mindweave/chap4.html

Harasim, L., Hiltz, S.R., Teles, L. \& Turoff, M. (1995). Learning networks: A field guide to teaching and learning online. Cambridge: Massachusetts Institute of Technology Press.

Holt, D.M., Rice, M. \& Armatas, C. (2002). Issues arising from an online resourcebased learning approach in first year psychology. In A. Williamson, C. Gunn, A. Young \& T. Clear (Eds), Winds of change in the sea of learning. Proceedings of the 19th Annual Conference of the Australasian Society for Computers in Learning in Tertiary Education (ASCILITE), vol.1, UNITEC, Auckland, New Zealand, 287-298. http:/ / www.unitec.ac.nz/ ascilite/ proceedings/ papers/ 050.pdf

Loyd, B.H. \& Gressard, C. (1984). Reliability and factorial validity of computer attitude scales. Educational and Psychological Measurement, 44, 501-505.

Mason, R. (1989). An evaluation of COSY on an Open University course. In R. Mason \& A. Kaye (Eds), Mindweave: Communication, Computers and Distance Education. Oxford: Pergamon, 115-45. http: / / icdl.open.ac.uk/literaturestore/mindweave/ chap9.html

McConnell, D. (2000). Implementing Computer Supported Cooperative Learning, London: Kogan Page.

McInnis, C. (2001). Signs of disengagement? The changing undergraduate experience in Australian universities. Inaugural Professorial Lecture, The University of Melbourne, Centre for the Study of Higher Education. [verified 30 Jul 2003] http: / / eprints.unimelb.edu.au / archive / 00000094/01/InaugLec23_8_01.pdf

Rowntree, D. (1997). Making Materials Based Learning Work: Principles, Politics and Practicalities, London: Kogan Page, Open and Distance Learning Series.

Salmon, G. (2000). E-moderating: The key to teaching and learning online, London: Kogan Page. 
Stacey, E. \& Fountain, W. (2001). Student and supervisor perspectives in a computer-mediated research relationship. In G. Kennedy, M. Keppell, C. McNaught \& T. Petrovic, (Eds). Meeting at the Crossroads. Proceedings of the 18th Annual ASCILITE Conference, 519-28. The University of Melbourne. http:/ / www.ascilite.org.au/conferences/melbourne01/pdf/papers/staceye.pdf

Stacey, E. \& Rice, M. (2002). Evaluating an online learning environment. Australian Journal of Educational Technology, 18(3), 323-340. http: / / www.ascilite.org.au / ajet/ajet18/ stacey.html

Thorpe, M. (1998). Assessment and 'third generation' distance education. Distance Education, 19(2), 265-86.

Weller M. (2001). Delivering Learning on the Net: The why, what and how of online education. London: Kogan Page.

Wenger, E. (1998). Communities of Practice Learning, Meaning, and Identity, Cambridge: Cambridge University Press.

\begin{tabular}{l|}
\hline Dale Holt and Mary Rice \\
Teaching and Learning Support Unit, Learning Services \\
Deakin University, Australia \\
dholt@deakin.edu.au, mrice@deakin.edu.au \\
Christine Armatas \\
School of Psychology, Faculty of Health and Behavioural Sciences \\
Deakin University, Australia \\
armatas@deakin.edu.au
\end{tabular}

